\title{
Call for Papers: Applied In Vitro Toxicology
}

\author{
Editor-in-Chief: James M. McKim, PhD, DABT; IonTox, LLC
}

Applied In Vitro Toxicology provides the latest peer-reviewed research on the application of alternative in vitro testing methods for predicting adverse effects in the pharmaceutical, chemical, and personal care industries. The Journal addresses important issues facing the various chemical industries, including regulatory requirements; the reduction, refinement, and replacement of animal testing; new screening methods; evaluation of new cell and tissue models; and the most appropriate methods for assessing safety and satisfying regulatory demands.

\section{Benefits of submitting include:}

- Fast and user-friendly electronic submission

- Rapid peer review and publication

- A diversity of article types

- Maximum exposure: readership in more than 170 countries worldwide

- Competitive Author Benefits Program

- Open access options available

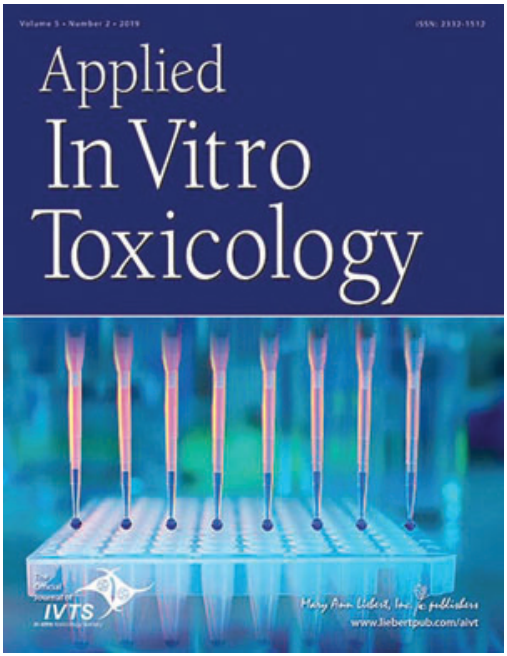

For complete author instructions and to submit your manuscript, please visit: liebertpub.com/manuscript/aivt

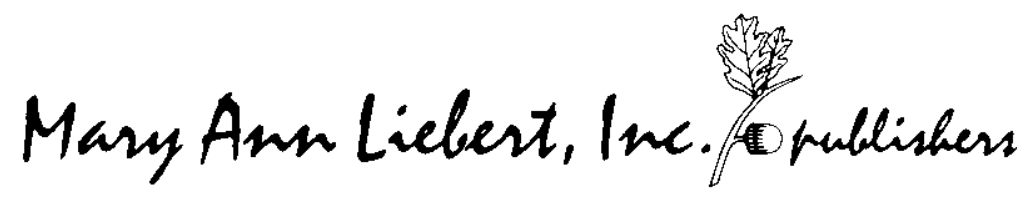

